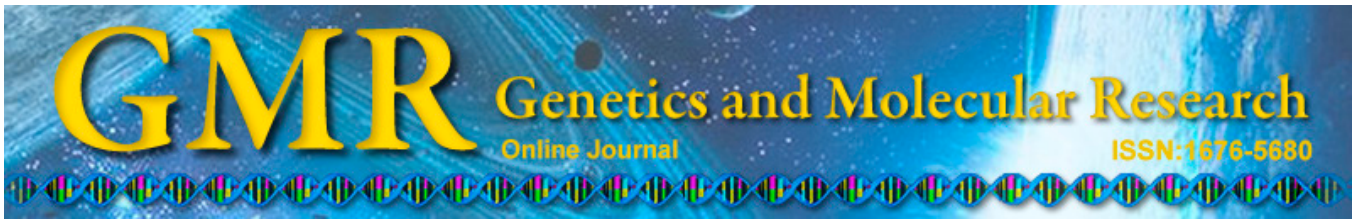

\title{
Human kallikrein 5 as a novel prognostic biomarker for triple-negative breast cancer: tissue expression analysis and relationship with disease course
}

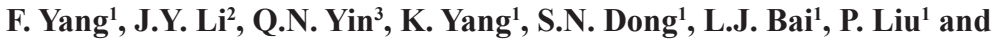 \\ X.W. Tong ${ }^{1}$ \\ ${ }^{1}$ Department of Obstetrics and Gynecology, Tongji Hospital, \\ Tongji University School of Medicine, Shanghai, China \\ ${ }^{2}$ Yicheng County Hospital, Shanxi, China \\ ${ }^{3}$ China Meitan General Hospital, Beijing, China \\ Corresponding author: F. Yang \\ E-mail: Yangf1983@gmail.com
}

Genet. Mol. Res. 14 (3): 9655-9666 (2015)

Received February 5, 2015

Accepted April 24, 2015

Published August 14, 2015

DOI http://dx.doi.org/10.4238/2015.August.14.28

\begin{abstract}
The purposes of this study were to analyze the expression and distribution of human kallikrein 5 (hK5) in triplenegative breast cancer (TNBC) tissues, to establish a standard operating procedure (SOP) for its immunohistochemical assay, and to evaluate the possibility of $\mathrm{hK} 5$ being a prognostic biomarker for TNBC. Recombinant hK5 protein and specific antibody were prepared, and the expression and distribution of hK5 in TNBC tissues were detected using immunohistochemistry. An SOP for immunohistochemical staining of hK5 in TNBC tissues was established to allow automatic staining under optimized conditions. The resulting images were digitized for evaluation and statistical analysis via a human scoring system. Our results showed that expression of hK5 protein could predict the progression of TNBC. Pearson's chi-square test results showed that high hK5 expression in
\end{abstract}


tumor stromal cells was significantly correlated with distal metastasis $(\mathrm{P}=0.039)$. A high staining score for lymphocyte infiltration in tumor stroma was significantly correlated with low histological grade of tumor $(\mathrm{P}=0.025)$. Univariate and multivariate $\mathrm{Cox}$ regression analyses verified that the staining score for hK5 in tumor stromal cells may be a biomarker for poor prognosis in TNBC patients (univariate $\mathrm{HR}=2.289$, $95 \% \mathrm{CI}=1.362-3.848, \mathrm{P}=0.002$; multivariate $\mathrm{HR}=2.105,95 \% \mathrm{CI}=$ 1.189-3.727, $\mathrm{P}=0.011)$. In conclusion, the expression level of hK5 in tumor stromal cells is a promising biomarker for poor prognosis in TNBC. Patients with high histological grade are more prone to distal metastasis and aggressive tumor progression.

Key words: Human kallikrein 5; Triple-negative breast cancer; Prognosis; Biomarker

\section{INTRODUCTION}

Triple-negative breast cancer (TNBC), an extremely dangerous, estrogen receptor (ER)-, progesterone receptor (PR)-, and human epidermal growth factor receptor 2 (HER2)depleted subtype of breast cancer, accounts for $10-17 \%$ of all breast cancer cases (Carey et al., 2006). The pathological manifestations of TNBC commonly include vigorous nuclear mitosis, considerable necrotic regions, lymphocyte infiltration, and irregular cell boundaries, and it mainly threatens women younger than 50 years old, with large tumor volumes and high invasive ability and recurrence rates, as well as short survival times (Krishnamurthy et al., 2012). Due to its lack of specific molecular targets, TNBC is insensitive to most hormonal therapies as well as those that target HER2. Although novel targeted therapies that use poly(ADP-ribose) polymerase inhibitors, epidermal growth factor inhibitors, and anti-angiogenesis agents have been developed, the efficacy and safety of their application in clinical practice remain unclear. Therefore, it is of great importance to find new biomarkers for TNBC that will benefit patients through enabling improved monitoring of tumor progression as well as enhancing the ability to predict prognosis and design personalized treatment protocols (Olopade et al., 2008).

As a highly conserved serine protease family comprising 15 members, human kallikrein-related peptidases (KLKs for genes and hKs for corresponding proteins) are located in the human chromosome 19q13.3-4 region and share $40-80 \%$ of their nucleotide sequences (Obiezu and Diamandis, 2005). The currently known hKs are single-stranded serine proteases, and the mature ones usually have highly conserved amino acid sequences around a residue in the catalytic center that is composed of His57, Asp102, and Ser195, and can specifically express serine proteases (Borgoño et al., 2004).

KLKs have been associated with the onset, progression, and invasion of tumors, especially steroid hormone-related types (e.g., ovarian, prostate, and breast cancers) (Clements et al., 2004). The abnormal expression of KLK5 in breast cancer tissues, in particular, has attracted wide attention.

While KLK5 is expressed at low to moderate levels in normal mammary tissues at both the mRNA and protein levels (Shaw and Diamandis, 2007), its mRNA expression is downregulated (Avgeris et al., 2011) but its protein expression is upregulated in breast cancer, which may allow early clinical diagnosis of the disease (Yousef et al., 2003). Meanwhile, 
downregulated expression of $K L K 5$ mRNA, like that of $K L K 1,-4,-7$, and -10 , is associated with poor clinical outcomes in breast cancer patients (Avgeris et al., 2010), commonly accompanied by short overall survival (OS) and disease-free survival (Yousef et al., 2002; Talieri et al., 2011). However, hK5 protein expression in breast cancer tissues has seldom been compared with clinical pathological data owing to the lack of specific and sensitive antibodies (Schmitt et al., 2013).

In particular, the predictive value of KLK5 in the clinical prognosis of TNBC had never previously been proved. In the current study, we examined the distribution and expression of hK5 protein in TNBC tissues, and explored the correlation between hK5 protein expression and clinical pathological characteristics, aiming to demonstrate that $\mathrm{hK} 5$ is a potential biomarker for the staging and typing of TNBC and for predicting its progression and clinical outcomes.

\section{MATERIAL AND METHODS}

\section{Preparation of recombinant hK5 protein}

Recombinant $\mathrm{hK} 5$ protein was designed and prepared in the molecular biology laboratory of Tongji University (Figure 1). In brief, KLK5 DNA was extracted from tumor cells, fused, and expressed in Escherichia coli through isopropyl- $\beta$-D-thiogalactoside-induced transfection. The expressed protein was labeled with a histidine (His) 6-tag beside the aminoterminal enterokinase (EK) cleavage site (DDDDK $\downarrow$ ), purified with nickel-nitrilotriacetic acid agarose chromatography, and subjected to renaturation and folding with oxidized and reduced glutathione. Detailed steps of recombinant protein preparation have been reported previously (Seiz et al., 2010).

\section{Recombinat KLK5}

\section{His6-tag}

$$
\text { EK }
$$

Figure 1. Main components of recombinant hK5 protein. hK5, human kallikrein 5.

\section{Preparation of anti-recombinant hK5 protein polyclonal antibody}

Anti-recombinant $\mathrm{hK} 5$ protein polyclonal antibody was prepared and purified in the experimental animal center of Tongji University. All the antibodies used are summarized in Table 1. Purified and recombinant hK5 proteins were injected into the popliteal lymph nodes of rabbits for the first immunization, followed by another 12 within five months thereafter. The resulting antibody was stored in citrated plasma at $-20^{\circ} \mathrm{C}$, and purified on an affinity chromatography column: (a) Preliminary screening on a chromatography column with embedded His and EK tags as well as non-KLK5-related sequence fragments; (b) secondary purification on a chromatography column with embedded KLK5 immunogen. The detailed steps of the purification procedure have been reported previously (Seiz et al., 2010). 


Table 1. Anti-recombinant hK5 protein antibody.
\begin{tabular}{lccl}
\hline Antibody & Immunized species & Immunogen & Purification \\
\hline anti-KLK5 & Rabbit & rec-KLK5 & $\begin{array}{l}\text { A: His/EK and non-hK5 fragment } \\
\text { B: rec KLK 5 }\end{array}$ \\
\hline
\end{tabular}

\section{Tissue samples from TNBC patients}

A total of 180 TNBC patients who underwent surgery between September 15, 2003 and September 26, 2009 in the Department of Obstetrics and Gynecology, Tongji Hospital, Tongji University School of Medicine were selected and followed up until September 2013. This study was approved by the ethics committee of our hospital, and written consent was obtained from all patients. The tumor tissue samples were collected according to standard pathological procedures and stored in liquid nitrogen for no longer than 120 months. The tumor samples were then prepared into tissue microarrays (Skacel et al., 2002) to detect the expression levels of ER, PR, and HER2. Classification of samples as ER- or PR-indicates that the level of nuclear immunohistochemical staining was lower than $10 \%$, and classification as HER2- indicates that the level of immunohistochemical staining was $0-1+$ or that HER-2 was not overexpressed, as detected by the fluorescence in situ hybridization method. The screened samples were then subjected to immunohistochemical assay, and statistical analysis was performed on the samples as well as on clinical follow-up data. Finally, 158 cases with complete follow-up data were analyzed after exclusion of samples lost during preparation and staining.

\section{Immunohistochemical assay and evaluation}

All tissue microarrays were first subjected to routine hematoxylin and eosin staining to recognize cells and tissues with abnormal structures and to locate tumor cells, tumor stromal cells, lymphocyte infiltration, and necrotic regions. By using horseradish peroxidase-labeled streptavidin-biotin, staining was performed with a Ventana BenchMark ${ }^{\circledR}$ XT staining system (Ventana Medical Systems, Inc., Tucson, AZ, USA). Afterwards, the stained microarrays were scanned with a high-resolution Hamamatsu NanoZoomer HAT slide scanner (Hamamatsu, Hamamatsu City, Japan) based on the linear scanning technology, and the images were evaluated independently by two experienced pathological experts, with the mean of the two results used. The scoring system was based on the semi-quantitative immunoreactive score (IRS) method of Remmele and Stegner (1987). The staining intensities and positive rates/ranges of tumor cells, tumor stromal cells, lymphocyte infiltration, and necrotic regions were scored respectively. Scoring for staining intensity: 0 - unstained; 1 - weak; 2 - moderate; 3 - strong. Scoring for positive rate/range (based on the percentage of stained cells to total ones): 1 , $<10 \% ; 4,>80 \%$. The two scores were multiplied and used as the final IRS. Values for tumorscoring (TS), stroma-scoring (SS), lymphocyte-scoring (LS) and necrotic-scoring (NS) were obtained. The scoring was conducted in triplicate, with the mean used for statistical analysis.

\section{Statistical analysis}

All data were analyzed using SPSS 20 (IBM SPSS Statistics Version 20, Armonk, NY, USA), with two-tailed tests and with a $\mathrm{P}$ value $\leq 0.05$ denoting a statistically significant dif- 
ference. Correlations between the hK5 expression scores of human and automatic evaluation systems were subjected to Spearman's rank correlation analysis, with a correlation coefficient $\geq 0.5$ indicating a strong correlation. The missing data were excluded in pairs. Relationships between hK5 expression level and clinical pathological characteristics were analyzed using Pearson's chi-square $\left(\chi^{2}\right)$ test. Fisher's exact test was used when the expected values were less than 5. Clinical outcomes were assessed with OS (the time from surgery to death) and time to progression (TTP) (the time from surgery to tumor progression or tumor-induced death). OS and TTP were employed as the endpoints of follow-up, the effect of clinical pathological characteristics, and hK5 expression level, which were analyzed with univariate and multivariate Cox regression models. The multivariate Cox regression model was adjusted by considering known prognostic factors of breast cancer, including age, tumor size, lymphatic invasion, nuclear grading, and pathological typing. The final related factors were added in the model by using the Forward and Enter methods. Statistical differences were reflected with risk factors, $95 \% \mathrm{CI}$, and P value. Survival curves were plotted using the Kaplan-Meier method, and statistical differences were compared with the log-rank test.

\section{RESULTS}

\section{Clinical pathological data of TNBC patients}

The selected patients were aged $27-85$ years (median: 57 years). The high proportions of young $(32.9 \%,<50$ years) and premenopausal patients $(28.5 \%)$ are consistent with previous reports (Foulkes et al., 2010). Pathological and morphological characteristics, such as tissue typing, TNM staging, nuclear grading, and lymphatic infiltration, were recorded. Of the 158 cases, most (77.2\%) were invasive ductal carcinomas, and the others included medullary carcinoma, invasive lobular carcinoma, and other types. The tumors were classified based on the American Joint Committee on Cancer (AJCC) TNM system, and graded as G1/2/3 based on the Nottingham grading system. TNBC patients were generally characterized by high tumor grade (G3, 82.3\%), high risk of metastasis $(32.3 \%)$, and high recurrence rate $(16.5 \%)$, findings that are in accordance with previous studies (Bonzanini et al., 2012). At the end of follow-up, 65 patients $(41.1 \%)$ had died, and 68 (43\%) had experienced disease progression. The medians for OS and TTP were 60 and 39 months, respectively. Ninety-six patients $(60.8 \%)$ received chemotherapy based on anthracenes or cyclophosphamides, $26(16.5 \%)$ received endocrinotherapy, $110(69.6 \%)$ received radiotherapy, and $6(3.8 \%)$ received immunotherapy. In addition, 13 patients underwent preoperative neoadjuvant chemotherapy. Notably, lymphocyte infiltration was observed in most samples, with 125 cases $(79.1 \%)$ of mild infiltration and 26 cases $(16.5 \%)$ of moderate infiltration. Moreover, there were wide necrotic regions in 42 samples $(26.6 \%)$. All these findings are consistent with the known pathological features of TNBC tissues and cells (Bonzanini et al., 2012). The clinical, pathological, histological, and morphological data are listed in Table 2.

\section{Expression of $\mathrm{hK5}$ protein in $\mathrm{TNBC}$ tissues}

Immunohistochemical assay showed that tissue microarrays had similar staining characteristics, only slightly differing in the intensity and region. There were different extents of 
staining in the cytoplasms of mammary and luminal epithelial cells, and a few cell nuclei were stained. In general, the automatically stained brown particles were mainly distributed in glandular and luminal epithelial tumor cells, and in a small amount of tumor stromal cells. The staining intensities and ranges for tumor cells and stromal cells in different patients differed significantly (Figure 2).

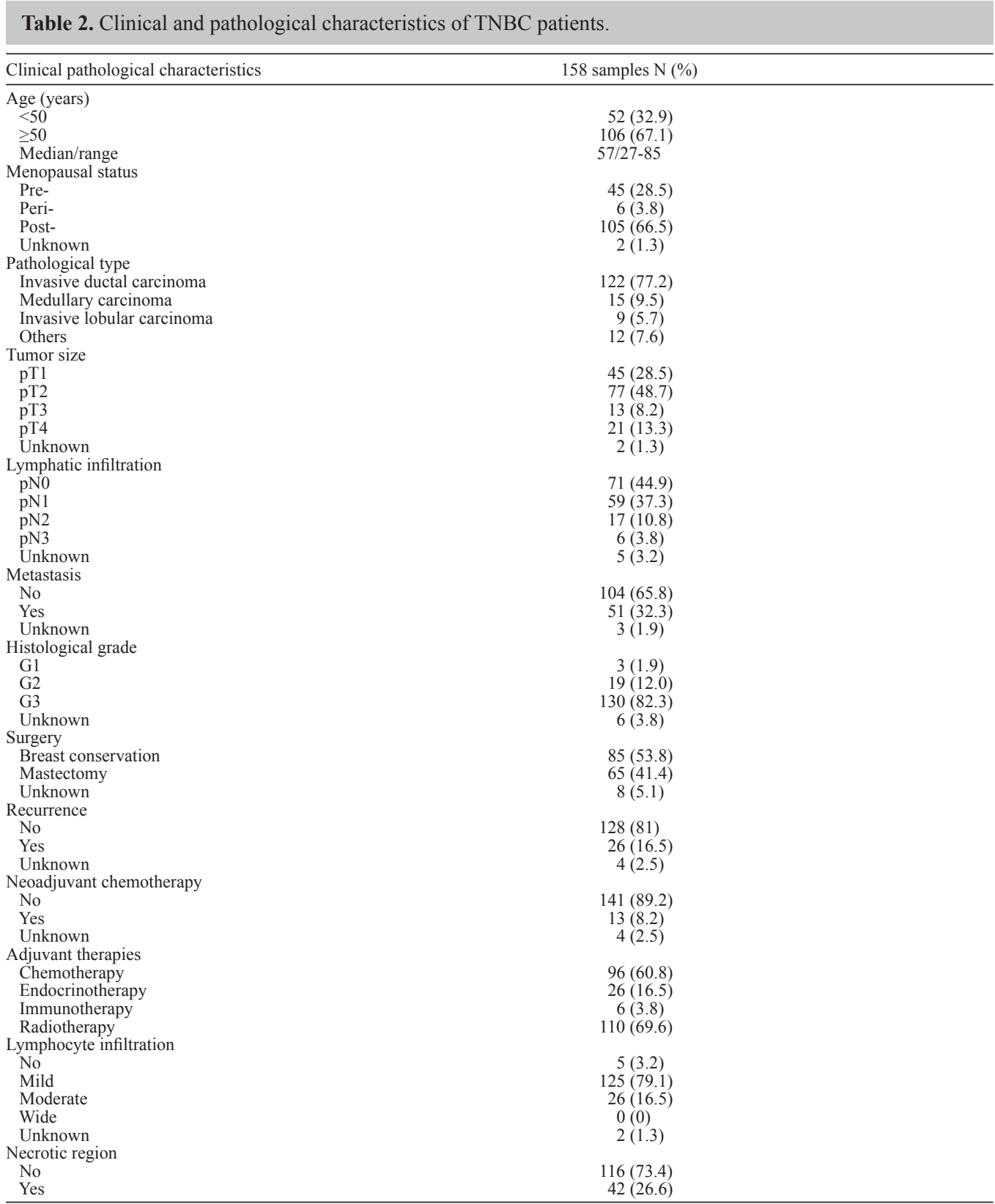



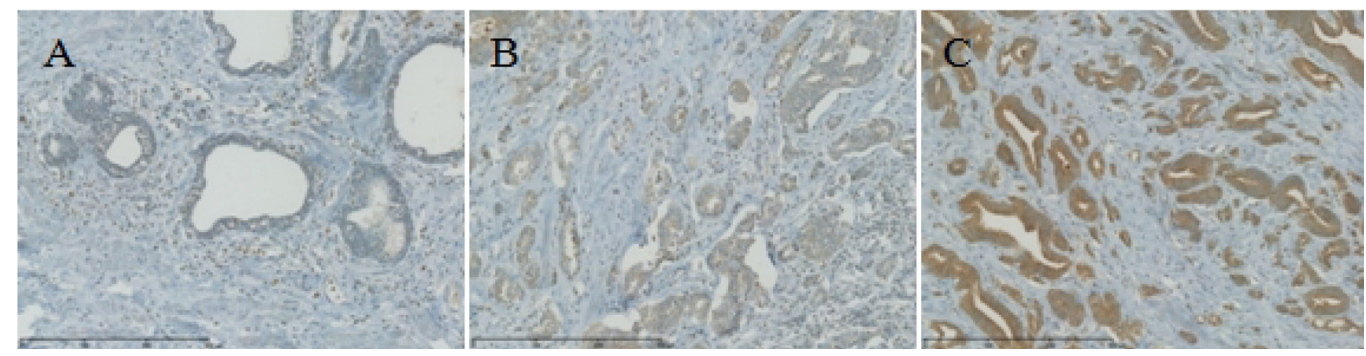

Figure 2. Automatic KLK5 staining in TNBC tissue microarrays. Ventana ultraView ${ }^{\circledR}$ method (A) essentially without hK5 staining; (B) weak staining in tumor cell cytoplasm and no staining in stromal cells; (C) strong staining in tumor cell cytoplasm and weak staining in stromal cells. Magnification 200X. KLK5 = kallikrein-related peptidase $5 ; \mathrm{TNBC}=$ triple-negative breast cancer; hK5 = human kallikrein 5.

\section{Correlations between $\mathrm{hK5}$ protein expression and clinical pathological parameters}

Correlations between $\mathrm{hK} 5$ protein immunoscores and clinical pathological parameters were analyzed using Pearson's chi-square test (Table 3). High KLK5-SS was significantly correlated with distal metastasis $(\mathrm{P}=0.039)$, and high pathological grade was strongly correlated with hK5-LS ( $\mathrm{P}$ $=0.025)$. In addition, menopausal status (pre-/peri-) was significantly correlated with hK5-TS $(\mathrm{P}=$ 0.036). However, hK5 immunoscores were not correlated with other clinical pathological parameters.

\begin{tabular}{|c|c|c|c|c|c|}
\hline Clinical path & No. & High TS $(>0)$ & High SS $(>1)$ & High LS $(>1)$ & High NS $(>0)$ \\
\hline$\overline{\text { Age (years) }}$ & $P$ & 0.311 & 0.363 & 0.143 & 0.652 \\
\hline$\leq 50$ & 52 & $28(53.8 \%)$ & $30(57.7 \%)$ & $28(53.8 \%)$ & $15(28.8 \%)$ \\
\hline$>50$ & 106 & $48(45.3 \%)$ & $53(50.0 \%)$ & $44(41.5 \%)$ & $27(25.5 \%)$ \\
\hline Menopause & $\mathrm{P}$ & 0.036 & 0.186 & 0.061 & 0.779 \\
\hline Pre-/peri- & 51 & $31(60.8 \%)$ & $31(60.8 \%)$ & $29(56.9 \%)$ & $13(25.5 \%)$ \\
\hline Post- & 105 & $45(42.9 \%)$ & $52(49.5 \%)$ & $43(41.0 \%)$ & $29(27.6 \%)$ \\
\hline Tumor size & $\mathrm{P}$ & 0.167 & 0.194 & 0.204 & 0.227 \\
\hline $\mathrm{pT} 1+\mathrm{pT} 2$ & 122 & $63(51.6 \%)$ & $60(49.2 \%)$ & $58(47.5 \%)$ & $34(27.9 \%)$ \\
\hline $\mathrm{pT} 3+\mathrm{pT} 4$ & 34 & $13(38.2 \%)$ & $21(61.8 \%)$ & $12(35.3 \%)$ & $6(17.6 \%)$ \\
\hline Node status & $\mathrm{P}$ & 0.138 & 0.882 & 0.125 & 0.348 \\
\hline $\mathrm{pN} 0+\mathrm{pN} 1$ & 130 & $67(51.5 \%)$ & $70(53.8 \%)$ & $62(47.7 \%)$ & $33(25.4 \%)$ \\
\hline $\mathrm{pN} 2+\mathrm{pN} 3$ & 23 & $8(34.8 \%)$ & $12(52.2 \%)$ & $7(30.4 \%)$ & $8(34.8 \%)$ \\
\hline Metastasis & $\mathrm{P}$ & 0.817 & 0.039 & 0.249 & 0.402 \\
\hline No & 104 & $51(49.0 \%)$ & $49(49.5 \%)$ & $51(49.0 \%)$ & $26(25.0 \%)$ \\
\hline Yes & 51 & $24(47.1 \%)$ & $33(64.7 \%)$ & $20(39.2 \%)$ & $16(31.4 \%)$ \\
\hline Grade & $P$ & 0.056 & 0.688 & 0.025 & 0.578 \\
\hline $\mathrm{G} 1 / 2$ & 22 & $15(68.2 \%)$ & $11(50.0 \%)$ & $5(22.7 \%)$ & $5(22.7 \%)$ \\
\hline G3 & 130 & $60(46.2 \%)$ & $71(54.6 \%)$ & $63(48.5 \%)$ & $37(28.5 \%)$ \\
\hline Recurrence & $\mathrm{P}$ & 0.474 & 0.062 & 0.937 & 0.661 \\
\hline No & 128 & $64(50.0 \%)$ & $63(49.2 \%)$ & $58(45.3 \%)$ & $34(26.6 \%)$ \\
\hline Yes & 26 & $11(42.3 \%)$ & $18(69.2 \%)$ & $12(46.2 \%)$ & $8(30.8 \%)$ \\
\hline
\end{tabular}

Chi-square test, cutoff point: median. TS = tumor-scoring; SS = stroma-scoring; LS = lymphocyte-scoring; NS = necrotic-scoring. Numbers in bold indicate the impact of clinical pathological parameters and hK5 expression level of these patient samples on TNBC survival.

\section{Correlations between clinical pathological parameters, $\mathrm{hK5}$ expression, and survival rate of TNBC}

Univariate and multivariate Cox regression analyses were employed to study the cor- 
relations between clinical pathological characteristics, hK5 protein expression levels, and OS and TTP. Univariate regression analysis was first performed to assess the relationships of known clinical prognostic indices (age, tumor size, lymphatic invasion, and histological grade) and other pathological parameters (menopausal status, distal metastasis, recurrence, and surgical method) with survival. Meanwhile, hK5 immunoscores were subjected to independent survival analyses. The factors with statistical significance were then considered in multivariate Cox regression analysis to calculate their risk factors and 95\%CIs. Survival curves were plotted using the Kaplan-Meier method, and statistical differences were compared with the log-rank test.

\section{Predictive values of clinical pathological parameters and hK5 expression level in OS and TTP}

Univariate regression analysis showed that age ( $>50$ years), tumor size (pT3/4), lymphatic infiltration (pN2/3), distal metastasis, recurrence, and surgical method (mastectomy) could predict short OS in TNBC patients, with statistically significant predictive values. Nevertheless, the hK5 immunoscores of either tumor cells or tumor stromal cells had very little effect on OS. Tumor size, lymphatic infiltration, and surgical method were also univariate predictive factors of TTP. Notably, hK5-SS was significantly correlated with TTP $(\mathrm{HR}=2.289$, $95 \% \mathrm{CI}=1.362-3.848, \mathrm{P}=0.002)($ Table 4$)$.

The effective factors were then considered in a multivariate regression model that included histological grade with the Forward logistic regression method. Lymphatic infiltration, histological grade, and distal metastasis were correlated with short OS, and distal metastasis exerted the most significant effect $(\mathrm{HR}=7.087,95 \% \mathrm{CI}=3.776-13.301)$. Surprisingly, in addition to lymphatic infiltration, hK5-SS also significantly affected tumor progression (HR = $2.105,95 \% \mathrm{CI}=1.189-3.727, \mathrm{P}=0.011)$. These results suggest that the $\mathrm{hK} 5$ protein expression level may be an independent prognostic factor for TNBC patients (Table 5).

Kaplan-Meier analysis revealed the influence of hK5 immunoscores on tumor progression. High hK5-SS (green line) significantly predicted high risks of metastasis and recurrence $(\mathrm{P}=0.001)$ (Figure 3). According to the Kaplan-Meier curves and Cox regression analysis results, hK5 antigen levels of tumor stromal cells evidently affected tumor grade, metastasis, and TTP, and a high hK5 protein expression level significantly predicted a high risk of metastasis and short TTP, indicating that hK5 expression in tumor stromal cells is an independent predictive factor for rapid TNBC progression.

\section{DISCUSSION}

The antibody we prepared was able to specifically recognize and detect hK5 antigen in human TNBC cells and tissues. More importantly, similar to the findings of previous studies, hK5 protein was mainly distributed in the cytoplasms of glandular and luminal epithelial tumor cells, with only a small amount in the cell nuclei. Hence, hK5 is a typical secretory protein. The hK5 protein has two isoforms in serum and ascites, respectively, with molecular weights of about 50 and 150-180 kDa (Yousef et al., 2003), so it may bind protease inhibitors or other reactive proteins in tumor tissues to generate structurally and functionally different isoforms. 


\begin{tabular}{|c|c|c|c|c|}
\hline \multirow[t]{2}{*}{ Variable } & \multicolumn{2}{|c|}{ OS } & \multicolumn{2}{|c|}{ TTP } \\
\hline & HR $(95 \% \mathrm{CI})$ & $\mathrm{P}$ & $\mathrm{HR}(95 \% \mathrm{CI})$ & $\mathrm{P}$ \\
\hline \multicolumn{5}{|l|}{ Age (years) } \\
\hline $\begin{array}{l}\leq 50 \\
>50\end{array}$ & $2.251(1.200-4.223)$ & 0.012 & $0.814(0.477-1.388)$ & 0.450 \\
\hline \multicolumn{5}{|l|}{ Menopause } \\
\hline $\begin{array}{l}\text { Pre-/peri- } \\
\text { Post- }\end{array}$ & $1.713(0.959-3.058)$ & 0.069 & $1.091(0.649-1.835)$ & 0.741 \\
\hline \multicolumn{5}{|l|}{ Grade } \\
\hline $\begin{array}{l}\mathrm{G} 1 / 2 \\
\mathrm{G} 3\end{array}$ & $1.632(0.775-3.437)$ & 0.198 & $1.580(0.752-3.318)$ & 0.227 \\
\hline \multicolumn{5}{|l|}{ Tumor size } \\
\hline $\begin{array}{l}\mathrm{pT} 1 / 2 \\
\mathrm{pT} 3 / 4\end{array}$ & $3.817(2.277-6.401)$ & $<1 \times 10^{-6}$ & $3.419(2.041-5.729)$ & $<1 \times 10^{-6}$ \\
\hline \multicolumn{5}{|l|}{ Nodal status } \\
\hline $\begin{array}{l}\mathrm{pN} 0 / 1 \\
\mathrm{pN} 2 / 3\end{array}$ & $4.477(2.545-7.874)$ & $<1 \times 10^{-6}$ & $3.241(1.806-5.816)$ & 0.000081 \\
\hline \multicolumn{5}{|l|}{ Metastasis } \\
\hline $\begin{array}{l}\text { No } \\
\text { Yes }\end{array}$ & $9.728(5.544-17.068)$ & $<1 \times 10^{-6}$ & $15.403(8.318-28.522)$ & $<1 \times 10^{-6}$ \\
\hline \multicolumn{5}{|l|}{$\begin{array}{l}\text { Yes } \\
\text { Surgery }\end{array}$} \\
\hline $\begin{array}{l}\text { Breast conservation } \\
\text { Mastectomy }\end{array}$ & $3.384(1.995-5.740)$ & $<1 \times 10^{-6}$ & $2.392(1.452-3.940)$ & 0.001 \\
\hline \multicolumn{5}{|l|}{$\begin{array}{l}\text { Recurrence } \\
\text { Ren }\end{array}$} \\
\hline $\begin{array}{l}\text { No } \\
\text { Yes }\end{array}$ & $2.086(1.156-3.765)$ & 0.015 & $4.858(2.873-8.215)$ & $<1 \times 10^{-6}$ \\
\hline \multicolumn{5}{|l|}{$\begin{array}{l}\text { Yes } \\
\text { hK5-TS }\end{array}$} \\
\hline $\begin{array}{l}\text { Low } \\
\text { High }\end{array}$ & $0.843(0.515-1.380)$ & 0.497 & $0.983(0.603-1.595)$ & 0.945 \\
\hline \multicolumn{5}{|l|}{ hK5-SS } \\
\hline $\begin{array}{l}\text { Low } \\
\text { High }\end{array}$ & $1.485(0.903-2.441)$ & 0.119 & $2.289(1.362-3.848)$ & 0.002 \\
\hline \multicolumn{5}{|l|}{$\begin{array}{l}\text { High } \\
\text { hK5-LS }\end{array}$} \\
\hline $\begin{array}{l}\text { Low } \\
\text { High }\end{array}$ & $0.688(0.414-1.143)$ & 0.149 & $0.835(0.512-1.361)$ & 0.468 \\
\hline \multicolumn{5}{|l|}{$\begin{array}{l}\text { High } \\
\text { hK5-NS }\end{array}$} \\
\hline $\begin{array}{l}\text { Low } \\
\text { High }\end{array}$ & $1.505(0.903-2.508)$ & 0.117 & $1.349(0.808-2.251)$ & 0.252 \\
\hline
\end{tabular}

\section{Table 5. Multivariate Cox regression analysis for OS and TTP in TNBC patients.}

\begin{tabular}{|c|c|c|c|c|}
\hline \multirow[t]{2}{*}{ Variable } & \multicolumn{2}{|l|}{ OS } & \multicolumn{2}{|c|}{ TTP } \\
\hline & $\mathrm{HR}(95 \% \mathrm{CI})$ & $\mathrm{P}$ & HR $(95 \% \mathrm{CI})$ & $\mathrm{P}$ \\
\hline $\begin{array}{l}\text { Age ( } \leq 50 \text { years } v s>50 \text { years }) \\
\text { Menopause (pre-/peri- } v s \text { post-) }\end{array}$ & $0.695(0.328-1.475)$ & 0.343 & & \\
\hline Tumor size (pT1/2 vs $\mathrm{pT} 3 / 4)$ & $1.215(0.569-2.596)$ & 0.615 & $1.528(0.706-3.307)$ & 0.281 \\
\hline Nodal status (pN0/1 vs $\mathrm{pN} 2 / 3$ ) & $3.227(1.524-6.836)$ & 0.002 & $2.532(1.272-5.041)$ & 0.008 \\
\hline Metastasis (no $v s$ yes) & $7.087(3.776-13.301)$ & $<1 \times 10^{-6}$ & & \\
\hline Grade (G1/2 vs G3) & $3.583(1.438-8.925)$ & 0.006 & $1.571(0.709-3.477)$ & 0.266 \\
\hline Surgery (conservation $v s$ mastectomy) & $2.205(0.977-4.200)$ & 0.058 & $1.905(0.973-3.732)$ & 0.060 \\
\hline Recurrence (no vs yes) & $1.813(0.930-3.534)$ & 0.080 & & \\
\hline \multicolumn{5}{|l|}{ hK5-TS (low vs high) } \\
\hline hK5-SS (low vs high) & & & $2.105(1.189-3.727)$ & 0.011 \\
\hline hK5-LS (low vs high) & & & & \\
\hline hK5-NS (low vs high) & & & & \\
\hline
\end{tabular}




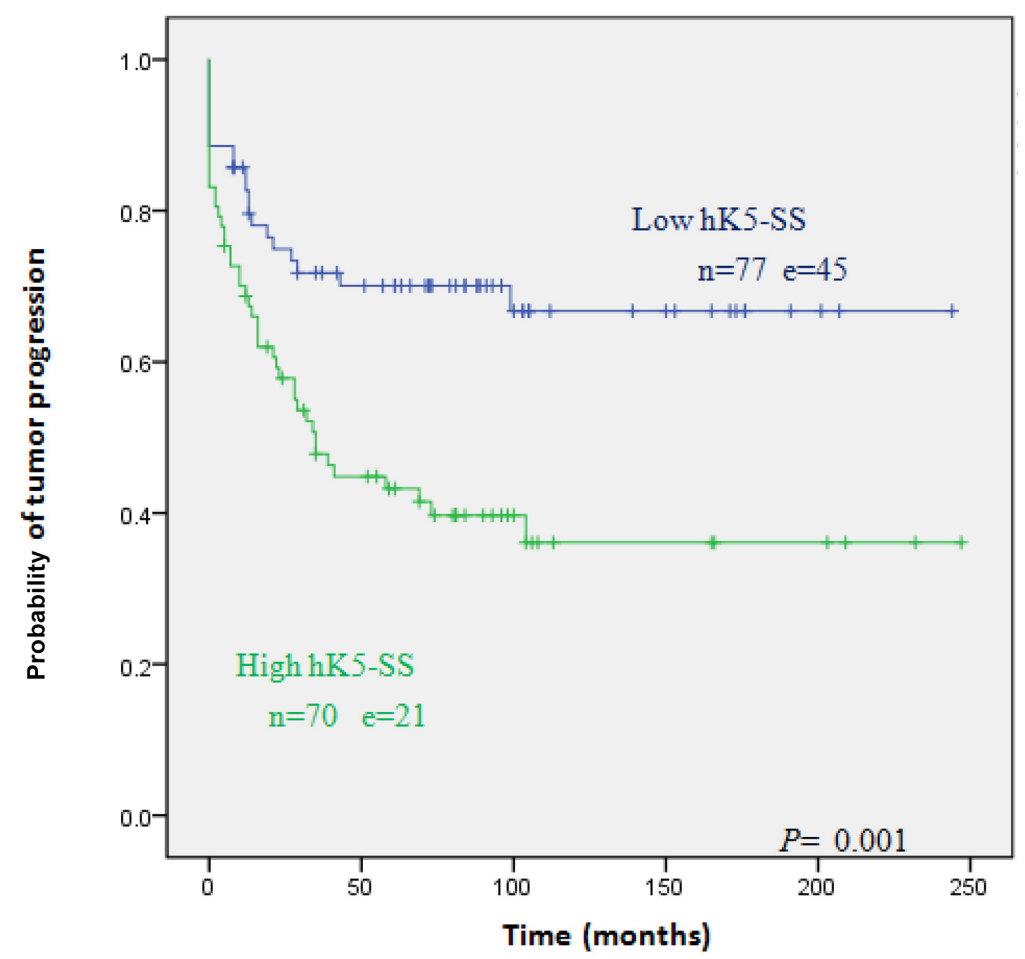

Figure 3. Kaplan-Meier curves for hK5 immunoscores on the probability of TTP $(\mathrm{N}=$ number of patients, $\mathrm{E}=$ number of events). Significance is assessed using the log-rank test. hK5 $=$ human kallikrein 5; TTP $=$ time to progression.

In this study, the immunohistochemical SOP demonstrated that tumor cells and tumor stromal cells were weakly and strongly stained, respectively. Pearson's chi-square test showed that hK5-SS was significantly correlated with distal metastasis and a high risk of tumor progression. Univariate and multivariate Cox regression analyses revealed that age, tumor size, lymphatic infiltration, histological grade, and hK5 protein expression level in tumor stromal cells may be prognostic factors for TNBC. Considering that most factors were grouped based on medians, the differences between clinical parameters might be more significant if higher percentiles were used instead. Regardless, our findings showed that hK5 protein expression still significantly predicted a high risk of metastasis and aggressive progression.

KLK5 not only directly degrades intercellular structure, extracellular matrix (ECM), and basement membrane components to facilitate cell loss at the end of epithelial regeneration (Stamenkovic, 2003), but also affects degradation of ECM, transformation of malignant cells, and tissue remodeling by cleaving ECM molecules (e.g., collagen I-IV, fibronectin and laminin) and cell adhesion molecules (e.g., fibrinogen and vitronectin). However, KLK5 can promote the transformation of plasminogen to release bioactive angiostatin-like fragments, thereby inhibiting generation of endothelial cells and capillary neogenesis (Michael et al., 2005). KLK5 can also promote the phosphorylation of extracellular signal-related kinase $1 / 2$ (ERK1/2) by activating the protease-activated receptor 2 (PAR2) pathway (Chung et al., 2012). Additionally, KLKs may participate in other signal transduction cascade pathways including 
the plasminogen activation system (Frenette et al., 1997) and matrix metalloproteinases (Egeblad and Werb, 2002). Furthermore, KLKs can be self-activated or activate other KLKs, which react with pro-KLK proteins as the substrates, thus forming a sophisticated intra- and extracellular network of proteolytic cascades (Bayés et al., 2004) that regulates cell morphology and affects cell motion, proliferation, and invasion. Therefore, KLK5 may be involved in signal transduction cascade pathways by activating similar cell growth factors, plasminogen, matrix metalloproteinases, and proteinase-activated receptors, which, together with self-activation and cross-activation, affect cell growth and adhesion molecules, cell surface receptors, and ECM components (Yousef and Diamandis, 2002). As a result, tumor onset, ECM degradation, and epithelial-mesenchymal transition are facilitated. Finally, KLK5 may play a crucial role in tumor growth, neovascularization, and distal metastasis. However, the detailed mechanisms of such activities still require in-depth studies.

\section{REFERENCES}

Avgeris M, Mavridis K and Scorilas A (2010). Kallikrein-related peptidase genes as promising biomarkers for prognosis and monitoring of human malignancies. Biol. Chem. 391: 505-511.

Avgeris M, Papachristopoulou G, Polychronis A and Scorilas A (2011). Down-regulation of kallikrein-related peptidase 5 (KLK5) expression in breast cancer patients: a biomarker for the differential diagnosis of breast lesions. Clin. Proteomics 8: 5.

Bayés A, Tsetsenis T and Ventura S (2004). Human kallikrein 6 activity is regulated via an autoproteolytic mechanism of activation/inactivation. Biol. Chem. 385: 517-524.

Bonzanini M, Morelli L, Bonandini EM, Leonardi E, et al. (2012). Cytologic features of triple-negative breast carcinoma. Cancer Cytopathol. 120: 401-409.

Borgoño CA, Michael IP and Diamandis EP (2004). Human tissue kallikreins: physiologic roles and applications in cancer. Mol. Cancer Res. 2: 257-280.

Carey LA, Perou CM, Livasy CA, Dressler LG, et al. (2006). Race, breast cancer subtypes, and survival in the Carolina Breast Cancer Study. JAMA 295: 2492-2502.

Chung H, Hamza M, Oikonomopoulou K, Gratio V, et al. (2012). Kallikrein-related peptidase signaling in colon carcinoma cells: targeting proteinase-activated receptors. Biol. Chem. 393: 413-420.

Clements JA, Willemsen NM, Myers SA and Dong Y (2004). The tissue kallikrein family of serine proteases: functional roles in human disease and potential as clinical biomarkers. Crit. Rev. Clin. Lab. Sci. 41: 265-312.

Egeblad M and Werb Z (2002). New functions for the matrix metalloproteinases in cancer progression. Nat. Rev. Cancer 2: 161-74.

Foulkes WD, Smith IE and Reis-Filho JS (2010). Triple-negative breast cancer. N. Engl. J. Med. 363: 1938-1948.

Frenette G, Tremblay RR, Lazure C and Dube JY (1997). Prostatic kallikrein hK2, but not prostate-specific antigen (hK3), activates single-chain urokinase-type plasminogen activator. Int. J. Cancer 71: 897-899.

Krishnamurthy S, Poornima R, Challa VR and Goud YG (2012). Triple negative breast cancer - our experience and review. Indian J. Surg. Oncol. 3: 12-16.

Michael IP, Sotiropoulou G, Pampalakis G, Magklara A, et al. (2005). Biochemical and enzymatic characterization of human kallikrein 5 (hK5), a novel serine protease potentially involved in cancer progression. J. Biol. Chem. 280: 14628-14635.

Obiezu CV and Diamandis EP (2005). Human tissue kallikrein gene family: applications in cancer. Cancer Lett. 224: 1-22.

Olopade OI, Grushko TA, Nanda R and Huo D (2008). Advances in breast cancer: pathways to personalized medicine. Clin. Cancer Res. 14: 7988-7999.

Schmitt M, Magdolen V, Yang F, Kiechle M, et al. (2013). Emerging clinical importance of the cancer biomarkers kallikrein-related peptidases (KLK) in female and male reproductive organ malignancies. Radiol. Oncol. 47: 319-329.

Seiz L, Kotzsch M, Grebenchtchikov NI, Geurts-Moespot AJ, et al. (2010). Polyclonal antibodies against kallikreinrelated peptidase 4 (KLK4): immunohistochemical assessment of KLK4 expression in healthy tissues and prostate cancer. Biol. Chem. 391: 391-401.

Shaw JL and Diamandis EP (2007). Distribution of 15 human kallikreins in tissues and biological fluids. Clin. Chem. 53: $1423-1432$. 
Skacel M, Skilton B, Pettay JD and Tubbs RR (2002). Tissue microarrays: a powerful tool for high-throughput analysis of clinical specimens: a review of the method with validation data. Appl. Immunohistochem. Mol. Morphol. 10: 1-6.

Stamenkovic I (2003). Extracellular matrix remodelling: the role of matrix metalloproteinases. J. Pathol. 200: 448-464.

Talieri M, Devetzi M, Scorilas A, Prezas P, et al. (2011). Evaluation of kallikrein-related peptidase 5 expression and its significance for breast cancer patients: association with kallikrein-related peptidase 7 expression. Anticancer Res. 31: 3093-3100.

Yousef GM and Diamandis EP (2002). Human tissue kallikreins: a new enzymatic cascade pathway? Biol. Chem. 383: 1045-1057.

Yousef GM, Scorilas A, Kyriakopoulou LG, Rendl L, et al. (2002). Human kallikrein gene 5 (KLK5) expression by quantitative PCR: an independent indicator of poor prognosis in breast cancer. Clin. Chem. 48: 1241-1250.

Yousef GM, Polymeris ME, Grass L, Soosaipillai A, et al. (2003). Human kallikrein 5: a potential novel serum biomarker for breast and ovarian cancer. Cancer Res. 63: 3958-3965. 